\title{
Oral contraceptive pills in the management of clomiphene resistant anovulation
}

\author{
Sangam K $\mathbf{K}^{1}$, Mitra $\mathbf{N}^{2}$ \\ ${ }^{1}$ Dr Sangam Kumari, MS, Assistant Professor, Obstetrics \& Gynaecology, L N Medical College, Bhopal, MP, India, ${ }^{2}$ Dr \\ Nishi Mitra, Assistant Professor, Obstetrics \& Gynaecology, L .N. Medical College, Bhopal, MP, India, ${ }^{3}$ Dr Anita Singh, \\ MS, DGO, DNB (ex-Associate Professor, Obs \& Gyne PMCH, Patna, India
}

Address for Correspondence: Dr Sangam Kumari, MS, Assistant Professor, Obstetrics \& Gynaecology, L.N. Medical College, Bhopal, Email- sangam.jha78@gmail.com.

\begin{abstract}
Introduction: We tried to evaluate the effectiveness of 2 months oral contraceptive pill (OCP) pretreatment for clomiphene citrate $(\mathrm{CC})$ resistant cases followed by repeat clomiphene citrate treatment. Material and Methods: In this study of 100 patients, 30 met the criteria of clomiphen citrate resistant anovulation. Before starting OCPs day 3 hormone profile assayed. All 30patients were given 2 months of continuous OCPs for hypothalamic -pituitary-ovarian axis suppression. After withdrawal bleeding, their day 3 hormonal profile assayed and clomiphene citrate was given from day 3-day7. Follicular growth monitored by sonography from day 12 till max size (>20mm) reached. 10,000 IU Hcg given to those patients who failed to show spontaneous rupture. Ovulation was confirmed by S. Progesterone assay on day 21. Pregnancy confirmed by S. Beta hCG level and 7 weeks amenorrhoea. Result: A total number of 30 patients completed 75 treatment cycles. 23 of them achieved ovulation. There were significant changes observed in hormonal profile in response to OCP treatment. 17 beta estradiol levels decreased to 58\%, 63\% reduction noted in LH level, androgen decreased by $56 \%$. FSH level also decreased but not so significantly. 23 patients ovulated out of 30 patients (76.6\%) which resulted in high ovulatory cycle 55/75 (73.2\%) and Cumulative pregnancy rate 60\% (18/30). Conclusion: This study showed the excellent ovulation and pregnancy rate following OCP suppression. This mode of treatment is a cheaper alternative to GnRH therapy for poor anovulatory women.
\end{abstract}

Key words : Folliculometry, Clomiphene Citrate Resistance, Oral Contraceptive Pills.

\section{Introduction}

Infertility cases account for $20-30 \%$ of women attending gynaecology outdoor and disorders of ovulation accounts for approx $30-40 \%$ of all cases of female infertility [1]. As ovulation is an obligatory prerequisite for conception, it must be documented as part of the basic assessment of the infertile couple. These disorders are among the most easily diagnosed and most treatable cause of infertility.

PCOD is the commonest cause of oligo-ovulation and anovulation. Traditionally clomiphene citrate has been the first line of intervention for medical induction of ovulation for last 50 years. It has been documented that $70-80 \%$ of women ovulate on clomiphene citrate and

Manuscript received: $1^{\text {st }}$ Oct 2015

Reviewed: $10^{\text {th }}$ Oct 2015

Author Corrected: $24^{\text {th }}$ Oct 2015

Accepted for Publication: $4^{\text {th }}$ Nov 2015
$30-40 \%$ among them will conceive eventually. For those patients who do not respond to clomiphene citrate, gonadotropin therapy or few adjunctive therapies are the next option. However exogenous gonadotropins therapy is costly and associated with risk of OHSS and multiple gestation. Adjunctive therapy's usefulness is limited to specific abnormalities. Many women with clomiphene citrate failure do not present with any overt sign of treatable disorders.

For these reasons there has always been a search for cheaper and convenient alternative regimen for ovulation induction in cc resistant women. It has been found by Branigan EF Ester study [1] that suppression of hypothalamic- pituitary-ovarian axis for 2 months with OCPs followed by repeat clomiphene citrate treatment results in excellent rate of ovulation and pregnancy in women. 


\section{Aims and Objective}

To study the response of repeat cc in terms of ovulation and pregnancy after giving 2 months of OCPs for hypothalamic- pituitary-ovarian axis suppression in women resistant to cc treatment .

\section{Materials and Methods}

The study was carried out in department of OBG, of tertiary care teaching hospital over a period of 2 years. 100 cases were selected from the patients who attended gynaecology OPD for infertility due to anovulation. All these selected patients had patent tubes ( documented by HSG) and husbands semen analysis within normal limits ( as per WHO criteria) [2]. They were given cc 50 $\mathrm{mg}$ from day 3 to day 7 . Ultrasound folliculometry started from day 12. If there was no follicular growth, next cycle stimulated with $100 \mathrm{mg} \mathrm{cc}$ and follicular monitoring done. $150 \mathrm{mg}$ cc dose was given in $3^{\text {rd }}$ cycle to those who did not ovulate on $100 \mathrm{mg}$.

All those who failed to ovulate at $150 \mathrm{mg}$ of(clomiphene citrate cc)were labelled as cc resistant. 30 patients who met the criteria were included in the study.

\section{Inclusion criteria:}

1. Documented anovulation at $150 \mathrm{mg}$ cc dose

2. Age $<35$ years

3. Patent tubes by HSG/ laproscopy

4. Normal fasting glucose \& insulin

5. Normal TSH \& Serum Prolactin

6. Normal FSH and estrogen

7. DHEAS <200mcg/dl

8. No contraindication to OCP use

9. Male partners had normal semen analysis

\section{Material \& Method}

Before starting OCPs Day 3 s. Beta -estradiol, LH , FSH, Testosterone and androstenidione measured.
All 30 patients received the low dose OCPs ( EE .03mg \& desogestrol $150 \mathrm{mg}$ ) continuously for 2 months. 7 days pill free interval was used to allow menstrual bleeding to occur. After withdrawal bleeding they were given $100 \mathrm{mg}$ cc from day3 to day 7 . Day $3 \mathrm{~s}$. Beta estradiol, FSH, LH, T, and androstenidione was assayed again.

Folliculometry started from day 12 and repeated every 1-2 days until mean diameter of dominant follicle was $>20 \mathrm{~mm}$. If the follicle mean diameter failed to grow $>1 \mathrm{~mm} /$ day after $14 \mathrm{~mm}$ or failed to reach to $14 \mathrm{~mm}$ by day 16 , monitoring stopped and cycle cancelled.

HCG $10,000 \mathrm{U}$ was given to those who failed to show spontaneous rupture after reaching $20 \mathrm{~mm}$ size. Follow up scan was performed 2 days after HCG injection or after DF> $20 \mathrm{~mm}$ size achieved.

USG sign of ovulation-

1. Disappearance of DF

2. Presence of fluid or increase in amount of fluid in POD.

3. Formation of echogenic cyst that was consistent with corpus luteum.

If these signs were present day $21 \mathrm{~S}$. Progesterone assayed to confirm ovulation (level $>15 \mathrm{mg} / \mathrm{ml}$ ). Endometrial growth was also monitored sonographically and endometrium pattern graded as per Gonen and Casper criteria [4].

Pregnancy was confirmed by S. beta HCG level and 7 weeks amenorrhoea. Pregnancy rate were recorded for each patient and treatment cycle.

Patients who ovulated but did not conceive in initial cycle were given $100 \mathrm{mg}$ cc from day 3 to day7 in next cycle and were monitored in same manner. This process was repeated for 6 cycles and results recorded.

\section{Result}

A total number of 30 patients completed 75 treatment cycles (mean 2-5 cycle).

Table-1: Age wise distribution of the patients

\begin{tabular}{|l|l|}
\hline Age in year & Number of patients \\
\hline $20-25$ & 10 \\
\hline $25-30$ & 13 \\
\hline $30-35$ & 7 \\
\hline
\end{tabular}


Most of the patient was in 20-30 years of age group with mean age of 28.1 years.

Table 2: Day 3 Endocrine profile before and after OCPs treatment

\begin{tabular}{|l|l|l|l|l|}
\hline Sl. no. & Hormones & OCP treatment & p-value \\
\cline { 3 - 5 } & & Before & After & .01 \\
\hline 1 & 17 beta - estradiol & $65+/-15$ & $27.7+/-3.6$ & NS \\
\hline 2 & FSH (IU/L) & 7.1 & 5.0 & 0.001 \\
\hline 3 & LH (IU/L) & 18.8 & 7.1 & .001 \\
\hline 4 & Testosterone $(\mathrm{ng} / \mathrm{dl})$ & $50.9+/-1.0$ & $22+/-3.2$ & 0.03 \\
\hline 5 & Androstenidione $(\mathrm{ng} / \mathrm{dl})$ & $2.2+/-0.9$ & $1+/-0.9$ & \\
\hline
\end{tabular}

There was significant decrease in $17 \beta$ estradiol, LH \& Androgen level following OCP treatment.

Table-3: Day 3 endocrine profile of the patients who did not ovulate on OCP + CC treatment cycle

\begin{tabular}{|l|l|l|l|}
\hline Hormone level & Before & After & P-value \\
\hline 1. 17 beta -estradiol (pg/ml) & $60+/-10$ & $30+/-6.4$ & 0.03 \\
\hline 2. FSH (IU/L) & 6 & 5.1 & NS \\
\hline 3. LH (IU/L) & 18 & 8 & 0.01 \\
\hline 4. Testosterone (ng/dl) & $54.7+/-18$ & $57.4+/-19$ & NS \\
\hline 5.Androstenidione (ng/dl) & $2.1+/-0.04$ & $1.9+/-0.2$ & NS \\
\hline
\end{tabular}

Of the seven patients who did not achieve ovulation, significant decrease in $17 \beta$ estradiol \& LH occurred but androgens were not changed significantly.

Table 4: Response to CC after OCPs treatment

\begin{tabular}{|l|l|}
\hline Ovulation (No ) & $23 / 30(76.6 \%)$ \\
\hline Ovulatory cycle (No) & $55 / 75(73.2 \%)$ \\
\hline Endometrium & $9.6+/-2.5 \mathrm{~mm}$ \\
\hline Cumulative pregnancy rate & $18 / 30(60 \%)$ \\
\hline
\end{tabular}

Out of 30 patients 23 ovulated which resulted in $73.2 \%$ of ovulatory cycle. Cumulative pregnancy rate is $60 \%$. Endometrium development is better following OCP treatment.

Table 5: Monthly cumulative pregnancy rate

\begin{tabular}{|l|l|l|}
\hline Month & Pregnancies & Cumulative PR \\
\hline 1 & 7 & $23 \%$ \\
\hline 2 & 3 & $34 \%$ \\
\hline 3 & 6 & $50 \%$ \\
\hline 4 & 1 & $57 \%$ \\
\hline 5 & 1 & $60 \%$ \\
\hline 6 & 0 & $60 \%$ \\
\hline
\end{tabular}

Most of the pregnancy occurred in first three cycle with only one in fourth and one in fifth cycle No pregnancy occurred in $6^{\text {th }}$ cycle.

\section{Discussion}

In this study mean age is 27.5 years. Women of > 35 years of age were excluded from the study as they need more prompt treatment. It has been shown by many studies that as age increases the chance of response to ovulatory induction regimen decreases. 
BMI is an important predictor of patients who will remain anovulatory. Mean BMI in this study was $27 \mathrm{~kg} / \mathrm{sq} \mathrm{m}$ but in the study of others as Emmet F. Branigan[1, 2] and Deepak Goenka [5] it was $30.3 \mathrm{~kg} / \mathrm{sqm}$ and $35 \mathrm{~kg} / \mathrm{sqm}$ respectively. Imani et al $[6,7]$ had emphasized that obese hyperandrogenic women are refractory to clomiphen citrate(cc).

In this study there was significant decrease in day 3 hormone level following OCPs suppression (58\% reduction in estradiol, 63\% in LH level, 56\% in Testosterone). FSH level decreased but not so significantly. These endocrine changes in early follicular phase may be responsible for improved ovarian response. This finding is in well correlation with the Emmet F. Branigan study [1,2] shown in Table 6. The decrease in ovarian androgens may be the most important of these changes.

Table 6: Comparison of hormone levels with other study

\begin{tabular}{|l|l|l|l|l|}
\hline & \multicolumn{2}{|l|}{ Current Study } & \multicolumn{2}{l|}{ Emmet F. Branigan [1] } \\
\hline Hormones & Before & After & Before & After \\
\hline 1.17 b-estradiol & $65+/-15$ & $27.7+/-3.6$ & $68+/-15$ & $25.7+/-2.6$ \\
\hline 2.FSH (IU/L) & 7.1 & 5 & 6.2 & 5 \\
\hline 3.LH (IU/L) & 18.8 & 7.1 & 17.8 & 7.1 \\
\hline 4.Testosterone(ng/dl) & $50.9+/-10$ & $22+/-3.2$ & $46.9+/-10$ & $21.3+/-3.2$ \\
\hline 5.Androstenidione (ng/dl) & $2.2+/-1.4$ & $1+/-0.9$ & $2.2+/-0.4$ & $1+/-0.9$ \\
\hline
\end{tabular}

In subgroup of patients who received OCPs but did not achieve ovulation while receiving repeat cc, their LH and betaestradiol decreased but not the androgen level. This finding is also supported by Imani et al [7] study which showed that patient with hyperandrogenaemia are poor responder to cc. Steinberger and Rodriguez Rigau [8] studied the relation of androgen suppression to pregnancy rates and found that more than $20 \%$ suppression resulted in $50 \%$ pregnancy rate. It has been shown by many studies that high level of intra-ovarian androgens is associated with impaired folliculogenesis, follicular atresia, poor oocyte maturation, delayed implantation and infertility. Ovary is the primary source androgens when D-sulfate is normal and ovarian steroidogenesis is better suppressed by OCPs. Testosterone level is significantly lowered in this study which is consistent with the finding of Ruchhoft E et al [9] that testosterone level is significantly lowerd during continuous regimen then compared to cyclic OCPs regimen.

In this study 23 out of 30 patients ovulated which resulted in $76.6 \%$ ovulation and ovulatory rate around $73.2 \%$ (55/ 75) and cumulative pregnancy rate at the end of 6 cycles were $60 \%$ (18/30). This is similar to observation by other studies shown in table 7.

Table 7: Comparison of ovulation \& cumulative pregnancy rates with other study

\begin{tabular}{|l|l|l|}
\hline Study & Ovulation & Cumulative pregnancy rate \\
\hline 1.Current study $(\mathrm{n}=30)$ & $76.6 \%$ & $60 \%$ \\
\hline 2.Emmet F. Branigan[2] $(\mathrm{n}=38)$ & $76 \%$ & $58 \%$ \\
\hline 3.Branigan and ester[1], $(\mathrm{n}=48)$ & $71 \%$ & $54 \%$ \\
\hline 4.Deepak Goenka[5], $(\mathrm{n}=46)$ & $67.39 \%$ & $52 \%$ \\
\hline
\end{tabular}

The improved pregnancy rate in this study was a result of decrease in miscarriage rate which is probably due to decrease in level of androgens and LH. LH has deleterious effect on preparation of endometrium for implantation. LH binding sites are present in the endometrium with highest concentration in luteal phase of the cycle. High LH concentration therefore has the potential to alter the local steroid or PGs metabolism and disrupt implantation. Many studies like Hamilton Fairely et al[10] \& Watson et al[11] showed the poor pregnancy outcome with high LH concentration.

This study's data suggest that OCPs treatment in anovulatory patients causes decrease in ovarian androgens level that allows clomiphene citrate to work more effectively. The decrease in ovarian androgen level following OCPs suppression is also supported by other studies (Erkind-Hirsh et al[12], and Genazzani et 
al[13] ) . This study suggests that hypothalamicpituitary-ovarian axis suppression with OCPs results in increase in pulsatile characteristic of $\mathrm{LH}$ with decrease in LH level and better development of endometrium.

Two months of continuous OCPs suppression was used in this study on the basis of pilot study (Branigh and Ester et al[1,2]) which showed that only $1 / 3^{\text {rd }}$ of the patient who will respond eventually with 2 months OCPs, will do so with 1 month suppression.

Low dose OCPs was chosen for this study as high dose has greater negative effect on return of fertility than low dose pills Bracken et al[14]. Desogestrel containing pills were used as it has low androgenic effect.

It has been shown by kjos et al study[15] that combined OCPs do not modify the risk of coronary artery disease or diabetes mellitus either negatively or positively. In long term it has got protective influence on endometrial cancer.

\section{Conclusion}

This study showed the excellent ovulation and pregnancy rate following 2 months of hypothalamic pituitary ovarian axis suppression with low dose OCPs. This improved ovulation rate and resulting pregnancies makes it clear cut alternative to gonadotropin therapy. This mode of treatment seems to be promising for those poor women who cannot afford costly gonadotropin ovulation induction regimen.

\section{Funding: Nil}

Conflict of interest: None.

Permission of IRB: Yes

\section{References}

1. Branigan EF, Estes MA. A randomized clinical trial of treatment of clomiphene citrate-resistant anovulation with the use of oral contraceptive pill suppression and repeat clomiphene citrate treatment. Am J Obstet Gynecol. 2003 Jun;188(6):1424-8; discussion 1429-30.

2. Branigan EF, Estes MA. Treatment of chronic anovulation resistant to clomiphene citrate (CC) by using oral contraceptive ovarian suppression followed by repeat CC treatment. Fertil Steril. 1999 Mar;71(3):544-6.
3. World Health Organization (1999) WHO Laboratory Manual for the Examination of Human Semen and Sperm-Cervical Mucus Interaction. 4th edn, Cambridge University Press, Cambridge.

4. Gonen Y, Casper RF. Prediction of implantation by the sonographic appearance of the endometrium during controlled ovarian stimulation for in vitro fertilization (IVF). J In Vitro Fert Embryo Transf. 1990 Jun;7(3):146-52.

5. Goenka Deepak, Goenka ML .Oral contraceptive pill pretreatment for clomiphene citrate resistant cases followed by repeat clomiphene citrate treatment . J Obstet Gynecol India.2006;56(2):159-161.

6. Imani B, Eijkemans MJ, Te Velde ER. A nomogram to predict the probability of live birth after clomiphene citrate ovulation in normogonadotropic oligomenorrheic infertility. Fertil Steril. 2002 Jan;77(1):91-7.

7. Imani B, Eijkemans MJ, te Velde ER, Habbema JD, Fauser BC. Predictors of patients remaining anovulatory during clomiphene citrate induction of ovulation innormogonadotropic oligoamenorrheic infert ility. J Clin Endocrinol Metab. 1998 Jul;83(7):2361-5.

8.Steinberger E, Smith KD, Tcholakian RK, RodriguezRigau Testosterone levels in female partners of infertile coupl es. Relationship between androgen levels in the woman, the male factor, and the incidence of pregnancy. Am J Obstet Gynecol. 1979 Jan 15;133(2):133-8.

9. Ruchhoft E, Elkind-Hirsch K, Malinak R. Pituitary function is altered during the same cycle in women with polycystic ovary syndrome treated with continuous or cyclic oral contraceptives or a gonadotropin-releasing hormone agonist. Fertility \& Sterility Jul 1996;66(1):54-60.

10. Hamilton-Fairley D, Franks S. Common problems in induction of ovulation. Baillieres Clin Obstet Gynaecol. 1990 Sep;4(3):609-25.

11. Watson H, Kiddy DS, Hamilton-Fairley D, Scanlon MJ, Barnard C, Collins WP, Bonney RC, Franks S. Hypersecretion of luteinizing hormone and ovarian steroids in women with recurrent early miscarriage. Hum Reprod. 1993 Jun;8(6):829-33. 
12. Elkind-Hirsch $\mathrm{KE}^{1}$, Anania C, Mack M, Malinak R. Combination gonadotropin-releasing hormone agonist and oral contraceptive therapy improves treatment of hirsute women with ovarian hyperandrogenism. Fertil Steril. 1995 May;63(5):970-8.

13. Genazzani AD, Petraglia F, Battaglia C, Gamba O, Volpe A, Genazzani AR. A long-term treatment with gonadotropin-releasing hormone agonist plus a lowdose oral contraceptive improves the recovery of the ovulatory function in patients with polycystic ovary syndrome. Fertil Steril. 1997 Mar;67(3):463-8.
14. Bracken MB, Hellenbrand KG, Holford TR. Conception delay after oral contraceptive use: the effect of estrogen dose. Fertil Steril. 1990 Jan;53(1):21-7.

15. Kjos SL, Peters RK, Xiang A, Thomas D, Schaefer U, Buchanan TA. Contraception and the risk of type 2 diabetes mellitus in Latina women with prior gestational diabetes mellitus. JAMA. 1998 Aug $12 ; 280(6): 533-8$.

\section{How to cite this article?}

Sangam K, Mitra N. Oral contraceptive pills in the management of clomiphene resistant anovulation. Int J Med Res Rev 2015;3(10):1182-1187. doi: 10.17511/ijmrr.2015.i10.213. 